\title{
Student Perceptions of Ethics, CSR, and Sustainability (ECSRS) in Hospitality Management Education
}

The purpose of this study is to examine how higher education students perceive ethics, corporate social responsibility (CSR), and sustainability (ECSRS) in regards to their current academic program and future career. Previous literature has shown an evolution in awareness for higher education institutions to implement ECSRS topics into their curriculum to better prepare students as future leaders. This quantitative study is based on a survey of 203 first year students to measure student levels of interest, perceived importance, and potential implementation of ECSRS in one international hospitality management school in Switzerland. This study has identified a gap between perceived knowledge, importance, and desire to learn about ECSRS within the hospitality management program. Based on student responses, there is a clear need and expectation that courses on ECSRS will be taught during their academic program to better prepare them for their future ambitions as well as the future of the planet. 150 words

Keywords: Ethics, CSR, Sustainability, higher education, hospitality management education

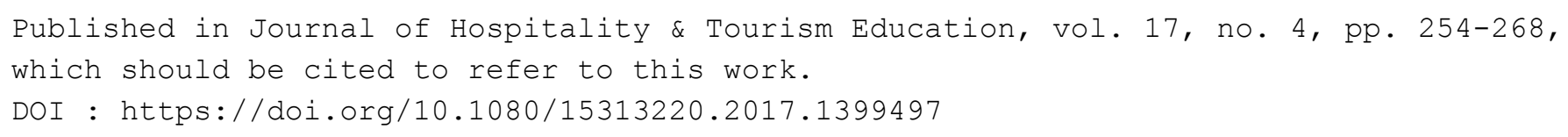




\section{Introduction}

Over the past few decades, the importance of ethics, corporate social responsibility (CSR), and sustainability (ECSRS) have been brought to the forefront as major corporations have received media attention in regards to their unethical behavior. Often corporate reputation and legitimacy are linked to CSR activities (Othman \& Othman, 2014), but some critics see it solely as a PR exercise (ibid). In response to these actions and as a preemptive measure to avoid future issues, the United Nations declared 2004-2015 as the 'Decade for Sustainable Development' (Seto-Pamies \& Papaoikonomou, 2016; Sidiropoulos, 2014) and introduced the Principle for Responsible Management Education (PRME) (Seto-Pamies \& Papaoikonomou, 2016) which is a voluntary global initiative to enhance and extend CSR and sustainability into mainstream education (Fernandez-Fernandez \& Sanjuan, 2010). The belief is that one way of limiting unethical and unsustainable behavior is through education. According to Seto-Pamies and Papaoikonomou (2016), 'academic institutions have the potential to generate a wave of positive change, thereby helping to ensure a world where both enterprises and societies can flourish' (UN, 2007, p. 3). For this reason, schools, especially higher education (HE) institutions, have begun offering courses to remediate unethical behavior and make students aware of their place in the global world.

In December 2016, 637 HE schools had already engaged with PRME and agreed to apply their six principles: purpose, values, method, research, partnership, and dialogue (http://www.unprme.org/). In short, by respecting the PRME principles, students will become future generators of sustainable values through academic activities, curricula, educational frameworks, research activities, interaction with managers and stakeholders in a supportive climate of dialogue and debate (http://www.unprme.org/). Some HE institutions seek specific accreditations such as EFMD Quality Improvement System (EQUIS) or Association to Advance Collegiate Schools of Business (AACSB) which acknowledge HE's efforts in 
teaching ECSRS. The EQUIS accreditation suggests that 'ethical, responsible, and sustainable behavior should be an integral part of business school's strategy and governance, as well as be reflected in their regular research, teaching, and service activities' (Cho et al., 2014, p. 2). The AACSB posits that 'management education must prepare students to contribute to organizations and the larger society and to grow personally and professionally throughout their careers' (Rundle-Thiele \& Wymer, 2010, p. 5) by establishing 'expectations for ethical behavior by ... students' (ibid, p. 5) and promoting 'a greater role for education on sustainable practices and corporate social responsibility in business schools' (Nicolls, Hair, Ragland, \& Schimmel, 2013, p. 129). These accreditation bodies and principles have shifted the emphasis from should ECSRS be implemented into HE to how ECSRS should be implemented in HE.

One of the greatest risks is the assumption that students have similar knowledge or views about ethics, CSR, or sustainability (Sidiropoulos, 2014). Generational stereotypes such as presuming that all Millennials are civic-minded and future positive social change agents can be wildly inaccurate and inconsistent (Costanza \& Finkelstein, 2015) and exclude appreciation of diversity and inclusiveness of individual differences (Lyons, Urick, Kuron, \& Schweiter, 2015). The idea that all Millennials search for meaningful, fulfilling work and a greater purpose in their jobs is preposterous at best as this would assume that they share similar values and attitudes regarding ethics, CSR, and sustainability and have equal skills and interest in making sustainable choices. HE could be the place where the less like-minded Millennials could come together and have an opportunity to develop an 'appreciation of (values), a disposition towards (attitudes), and a capability (skills) to make choices that contribute to sustainability (social and environmental good) instead of further detracting from it' (Sidiropoulos, 2014, p. 474). HE could, in fact, become a melting pot of diverse beliefs, practices, and actions for a common good, and not just a common diploma. 
Despite the many HE initiatives to incorporate ethics, CSR, and sustainability (ECSRS) into the curriculum, research projects, and on and off campus actions, no study has been found which addresses the question of whether business students want exposure to the topics of ethics, CSR, and sustainability (ECSRS) and whether they believe it is the responsibility of HE to deliver these topics. This study attempts to fill that gap by asking first year students to gauge the importance of the three topics in their student and professional lives to eventually propose new curriculum changes in one Bachelor's program in an international hospitality management school in Switzerland. Four research questions were defined:

RQ1: Are there differences between first and second semester students regarding their selfperceived knowledge of ECSRS?

RQ2: Do first year students rate ECSRS as more important in their academic or professional lives?

RQ3: Which of the three topics of ECSRS is deemed most important by first year students? RQ4: How would students prefer ECSRS to be introduced into the curriculum?

\section{Literature Review}

\section{Traditional responses in HE to ECSRS}

Previous research has shown a renewed emphasis on integrating ECSRS into institutional agendas and courses (Hesselbarth \& Schaltegger, 2014) and embedding environmental education and education for sustainable development (ESD) into education, research, campus operations, community outreach, assessment, and reporting (Lozano et al., 2015). HE developed and signed declarations, charters, and initiatives (DCI), but these do not guarantee the implementation of ECSRS in their establishments (ibid). Further, the literature has questioned the effectiveness of teaching ECSRS in higher education as following these courses does not ensure that students would behave the same way in a real life situation (Tormo-Carbo, Oltra, Segui-Mas, \& Klimkiewicz, 2016) which is often referred to as the 
'value-action gap' (Drayson, 2015; Savelyeva \& Douglas, 2017) or 'rhetoric-behavior gap' (Kopnina \& Meijers, 2013). These gaps demonstrate the difference between intention or motivation for making sustainable choices, and the harsh reality of choosing to implement them (Chaplin \& Wyton, 2014). Thus, the moment it is difficult or complicated to make a more sustainable choice, students may choose the easier option.

Traditionally, HE institutions have incorporated ECSRS on an institutional level, curricular level, and instrumental level. On an institutional level, ECSRS has been addressed by defining the mission and vision, establishing a ECSRS culture, incorporating ECSRS in strategic planning, appointing ECSRS coordinators, allocating budgets for ECSRS activities and initiatives, and designing ECSRS curriculum (Lozano et al., 2015; Seto-Pamies \& Papoikonomou, 2016; Verhulst \& Lambrechts, 2015). To ensure successful implementation of ECSRS in HE, specific professors who are interested in and passionate about ECSRS (Matten \& Moon, 2004) need to be identified as 'change agents' (Seto-Pamies \& Papoikonomou, 2016) or appointed as 'champions' or 'ambassadors' to lead ECSRS initiatives within the institution (Verhulst \& Lambrechts, 2015). These professors could incite students to become 'change agents' during their time in HE (ibid) and future 'corporate change agents' (Hesselbarth \& Schaltegger, 2014) or 'citizen-managers' in the workplace (GonzalezRodriguez, Diaz-Fernandez, Pawlak, \& Simonetti, 2013) who continue to proliferate the importance of ECSRS actions and initiatives. ECSRS must become a 'golden thread' throughout the entire HE institution (ibid) and part of the triple bottom line, and used as a marketing strategy for the institution (Othman \& Othman, 2014). This can be done through collaboration with the different stakeholders through increasing interaction and effective communication (ibid).

However, there are also many challenges to implementing ECSRS on an institutional level and these can often be linked to the four human factors which affect a change or shift by 
the institution toward the implementation of effective ECSRS teaching at HE level: resistance, communication, empowerment and involvement, and organizational culture (Verhulst \& Lambrechts, 2015). Resistance is evident when teachers believe their knowledge or skills may become irrelevant if a change or shift toward ECSRS is implemented in the curriculum. Issues commonly cited regarding resistance include lack of support, lack of resources and investment from stakeholders for ECSRS initiatives (Matten \& Moon, 2004), lack of time (Seto-Pamies \& Papoikonomou, 2016), sustainability-fatigue, and demotivation (Verhulst \& Lambrects, 2015). Communication breakdowns occur when there is a lack of shared understanding and common language between the various HE stakeholders, i.e. administration, teachers, students, regarding ECSRS strategy and implementation, specifically entailing questions such as which topics and methods should be used effectively by both students and staff (ibid). Empowerment and involvement are problematic unless HE can establish a common belief that the institution as a whole can perform well in important and valuable ECSRS tasks and experience a sense of significance from doing them while retaining independence and autonomy. While teachers have traditionally appreciated and expected to be 'masters' of their courses, where they are solely responsible for deciding the content and methodology as they see fit, they may feel ill at ease when faced with ECSRS concepts or topics due to lack of support or an already overcrowded curriculum (ibid). Thus, to encourage true empowerment and participation, these teachers must be willing and able to teach these topics (Matten \& Moon, 2004) and given the appropriate guidance or training when deemed necessary or requested.

Nonetheless, for the effect of resistance, communication, and empowerment/involvement to be thwarted or reduced, they must figure as a stalwart and strategic pole of the HE organizational culture which continues to replicate assumptions of actions from the past again and again in the future (Verhulst \& Lambrechts, 2015). On an 
organizational level, there may be limited perceived relevance, competing agendas, and dominant pedagogies (Seto-Pamies \& Papoikonomou, 2016) which traditionally drive the HE institution's strategic direction. Thus, if ECSRS actions could be successfully implemented into the organizational culture of HE institutions, they could become commonplace and widely accepted by the existing and future HE staff and students; the positive results of ECSRS would produce more positive results leading to a virtuous circle in HE.

Previous literature has also examined the implementation of ECSRS on a curricular level through course design and modules (Gonzalez-Rodriguez et al., 2013; Matten \& Moon, 2004; Seto-Pamies \& Papoikonomou, 2016; Sidiropoulos, 2014; Verhulst \& Lambrechts, 2015). While some studies focused on stand-alone courses (Seto-Pamies \& Papoikonomou, 2016), embedded courses (Seto-Pamies \& Papoikonomou, 2016; Verhulst \& Lambrechts, 2015), or a combination of both (Sidiropoulos, 2014), others concentrated on single discipline or multidisciplinary focus (Seto-Pamies \& Papoikonomou, 2016) or compulsory courses or modules versus optional electives or modules (Lozano et al., 2015; Matten \& Moon, 2004; Seto-Pamies \& Papoikonomou, 2016). While ECSRS could be offered in existing courses, modules, or degree programs such as economics or marketing courses (Sidiropoulos, 2014), ECSRS could also be offered as extracurricular activities to develop autonomy and ideological commitment (Seto-Pamies \& Papoikonomou, 2016) through service-learning experiences, learning communities, or volunteer projects (Gonzalez-Rodriguez et al., 2013). Student perceptions and preferences of how and where ECSRS could be implemented in one international hospitality school program in Switzerland are addressed in this paper.

ECSRS has also been examined on an instrumental level that of specific methodologies, pedagogies, and learning tools (Lozano et al., 2015; Seto-Pamies \& Papoikonomou, 2016; Sidiropoulos, 2014). By applying ECSRC theoretical concepts to reallife situations through excursions, internships, or volunteer projects (Seto-Pamies \& 
Papoikonomou, 2016), students become more aware of sustainability issues and shift their attitudes and actions accordingly (Sidiropoulos, 2014). ECSRS could also be offered through guest lecturers or part of continuous education (Lozano et al., 2015).

\section{Barriers for student engagement in ECSRS}

One of the greatest barriers for student engagement is student attitude toward the introduction of ECSRS courses and topics into their HE curriculum. While students may believe their actions are constructive and align with the principles of ECSRS that have learned in class (Stir, 2006), many students do not believe it is the role of HE to provide exposure to social issues (Sleeper, Schneider, Weber, \& Weber, 2006) or cover topics such as ECSRS in the classroom. In fact, offering ECSRS courses may have an adverse effect in the classroom as not all students will be receptive (ibid) and, for this reason, may have a negative influence on the class dynamics. While half of the students in one study believed that their environmental behavior has changed due to ECSRS exposure in HE, other students have gone as far as to suggest that ECSRS curriculum did not affect their perceptions of knowledge on this topic at all (Savelyeva \& Douglas, 2017). Thus, from a student perspective, there is a clear discrepancy between attitudes towards ECSRS in the HE setting.

For students who refute the necessity of ECSRS in HE, the question remains where they have attained or should attain their knowledge of ECSRS. According to the literature, friends and family do not seem to be important factors that influence student perceptions of their levels of sustainability consciousness, while school, the Internet, and the press do (Savelyeva \& Douglas, 2017). Through the press and the Internet, students are exposed to corporate scandals (Sleeper et al., 2006) and are inundated with messages, explanations, and apologies issued by these companies. While students with ECSRS education show higher ethical awareness of moral issues relating to business (Lau, 2010) and are more likely to question the motivations and ethics of big bosses (ibid), there is no guarantee that more 
training in ECSRS positively affects future corporate conduct (Fernandez-Fernandez \& Sanjuan, 2010). Further, regardless of the ECSRS information received during their HE experience, a large proportion of students are 'reluctant to put the sustainability performance of a potential employer on a higher priority during the career planning' (Yuan \& Zuo, 2013, p. 113). This suggests that knowledge of unethical behavior does not automatically constitute a negative opinion of a company or its practices. In the present study, students were asked to rate their perceptions of the importance of the three ECSRS topics both in school and in the workplace.

\section{Methodology}

This paper is based on 203 surveys collected from first and second semester students enrolled in an international hospitality management school in Switzerland. Students were given a brief 15-minute presentation on the general terms of ethics, CSR, and sustainability before responding to the survey. The purpose of the survey was to gauge how much first year students know about ECSRS, how important these topics are to them as students and as future employers, and how they could best see these topics fitting into their existing academic program.

In the short introduction preceding the survey, the three terms, ethics, CSR, and sustainability were defined to ensure that all students were responding to the questions based on a common understanding of the terms. Ethics was defined as 'a system of value principles that defines right and wrong behaviors' (Seto-Pamies \& Papaoikonomou, 2016, p. 525) whose value principles derive from education, upbringing, experience, or beliefs, and are often instilled from an early age. The definition of CSR was derived from The European Commission Report (2002) as 'a concept whereby companies integrate social and environmental concerns in their business operations and in their interaction with their stakeholders on a voluntary basis' (p. 5). The Brundtland Report (1987) defined sustainability 
as 'development that meets the needs of current generations without compromising the ability of future generations to meet their needs or aspirations' (p. 42). There was no further theory offered to the students to ensure their perceptions were representative of their pre-existing knowledge and opinions and not a replication of what they had just been told.

The survey consisted of 10 questions. In the first three questions, students were asked to rank on a scale of 1 to 10 their knowledge of ECSRS, their interest in ECSRS, and the importance of ECSRS to them as students and as future professionals. Students were then asked (questions four and five) to name three existing sustainable initiatives or actions taken on campus and suggest one new initiative which should be developed. Questions six and seven covered the topic of 'positive social change' and asked students if they had heard of the expression and if they would like to become positive social change agents. In question eight, students were asked in which specific courses ECSRS could be implemented effectively while in question nine, they were asked to suggest in which semester ECSRS topics would be best suited. Question ten was an open question which stated: 'In your opinion, what is the link between the hospitality industry and ECSRS?' There was no time limit for responding to these questions; nonetheless, most students had completed the survey within 15 minutes.

\section{Results}

\section{Descriptive statistics}

In this international hospitality management school in Switzerland, there are 84 different nationalities enrolled. Each of the classes is a mixture of these nationalities, thus, the data derived reflects different cultures, educational and personal experiences. The classes are also mixed by gender with a slight female majority. The ages for both semesters combined ranged from 19 to 26 . However, for this study, the variables of nationality, gender, and age were not examined. 


\section{Knowledge, interest, and importance of ECSRS}

For the first three questions, the results have been broken into first semester and second semester students (SEM1 and SEM2). In question one, students were asked to rank their knowledge about sustainability, CSR, and ethics on a scale from 1- 10 (1 being no knowledge at all; 10 being very knowledgeable). Results from question one can be seen on Table 1.

INSERT TABLE 1 HERE

As percentages, scores for sustainability ranged from $0 \%$ with absolutely no knowledge of sustainability for both semesters to the highest score of $25 \%$ with just over middle knowledge (score of 6) of sustainability for SEM1 and slightly higher percentage for SEM2 (30\%) with an overall ranking of 7. For CSR, scores 5 and under in knowledge prevailed for $76 \%$ of the SEM1 students compared to $60 \%$ for SEM2. The highest level of perceived knowledge was perceived in the category of ethics where $73 \%$ rated ethics knowledge as 6 or above compared to SEM 2 where $90 \%$ rated ethics knowledge at 6 or above.

Question $1 \mathrm{~b}$ asked students to clarify where they had gained their knowledge of ECSRS topics. The choices offered were: parents, friends, media, school, work, personal interest, none. The students could choose multiple responses. The results can be seen on Table 2.

INSERT TABLE 2 HERE

The strongest influence for disseminating knowledge about sustainability and CSR remains school, while parents rank first for teaching students about ethics. Work and personal research were the least likely places to gain knowledge about ECSRS. Of the three topics, CSR scored 20 students, both semesters combined, for never having learned about this topic. 
In question two, students were asked to rank their interest in learning about ECSRS topics on a scale of 1 to 10 ( 1 being not interested at all; 10 being extremely interested). The results can be seen on Table 3 .

INSERT TABLE 3 HERE

As seen on Table 3, interest in learning about sustainability is high with 94\% of SEM1 and $93 \%$ of SEM 2 students ranking their interest as 6 or above. For CSR, the interest is slightly lower at $71 \%$ for SEM1 and $85 \%$ for SEM2 students who rated their interest 6 or above. $83 \%$ of SEM1 and $92 \%$ of SEM 2 students rated their interest in learning about ethics as 6 or above on the scale.

In question three, students were asked to rank the importance of ECSRS to both their lives as students and future professional on a scale of 1 - 10 ( 1 being not important at all; 10 being extremely important). The results for the importance to their academic lives can be seen on Table 4.

INSERT TABLE 4 HERE

The scores for the importance of all three topics of ECSRS were substantially high. The scores for the importance of sustainability to their academic lives is quite positive with $98 \%$ of SEM1 students ranking its importance as 6 or above; out of 105 responses in that category, $77 \%$ of SEM1 students ranked the importance of sustainability at 8 or above on the scale. The results were similar for the SEM2 students where 95\% ranked the importance of sustainability at 6 or above, $79 \%$ at 8 or above. For CSR, SEM1 students ranked its importance (6 and above) at $88 \%$ while SEM2 students ranked CSR's importance at $94 \%$. While SEM1 students ranked the importance of ethics as 97\% (6 or above importance), SEM2 students ranked ethics' importance slightly lower at $91 \%$ (6 or above).

Students were also asked to rank the importance of ECSRS to their roles as future professionals. As seen in the literature, it is important that HE programs prepare students to be 
future managers and change agents. The results of students' perceptions regarding ECSRS on their professional careers can be seen on Table 5.

\section{INSERT TABLE 5 HERE}

In response to the question on the importance of sustainability to their future careers, SEM1 students responded favorably at $97 \%$ ( 6 and above), $88 \%$ at 8 or above. SEM 2 students showed equally strong results regarding the importance of sustainability for future careers at $99 \%$ for 6 or above and $85 \%$ at 8 and above. The importance of CSR for them as future professionals was rated 6 or above for $96 \%$ of SEM1 students and 99\% for SEM2 students respectively. For the importance of ethics for future professionals, 99\% of SEM1 students chose 6 or above compared to $95 \%$ of SEM2 students.

To examine how students imagined ECSRS courses to be implemented into the hospitality management curriculum, they were asked to choose between six options: one courses, embedded in all courses, one elective, one program, one degree, or externally. Students could choose multiple answers.

From the responses, it is clear that first year students, both semesters combined, prefer to learn about ECSRS through one course ( 75 responses), embedded in all courses (88 responses), one elective (51 responses), or externally (38 responses). The choice of embedding ECSRS had the strongest preference with 40 and 48 responses from SEM1 and SEM2 respectively. The choices of a program (29 responses) or degree based uniquely or heavily on ECSRS (10) seems much less attractive to first year students with one degree scoring the lowest for both semesters.

\section{Discussion}

From the results, it is clear that knowledge varies in regards to the three topics of ECSRS for first year students in this international hospitality management program in Switzerland. Both first and second semester students have more knowledge about ethics and 
sustainability than CSR, and, overall, the most knowledge recorded was for ethics. The relatively low scores for CSR knowledge could be explained by the fact that CSR is linked to corporations and students who have little work experience may not have encountered this term or any initiatives related to it thus far.

The literature suggests that friends and family do not have a significant effect on students' knowledge of ECSRS. The results in this study show the contrary. For both semesters, parents had a significant effect on students' knowledge of sustainability and ethics, with a lesser effect on their knowledge of CSR. Friends also influenced their knowledge of ethics primarily, followed by sustainability and CSR. Still, school had the greatest influence on students' knowledge for both semesters combined. School scored highest in sustainability knowledge, followed by CSR, and ethics. This is the one area where CSR did not score the lowest; however, this result seems to contradict the low scores in question one regarding their perceived knowledge level of CSR. If students had truly learned about CSR in school prior to completing this survey, it could be assumed that they would have higher levels of knowledge on this topic. That is seemingly not the case in this study.

Nonetheless, it is encouraging to see the interest in learning about ECSRS in this hospitality management program is high. From Table 3, it is clear that students are most interested in learning about sustainability at $93.5 \%$ average for the two semesters combined. Students appeared least inclined to want to learn about CSR at $71 \%$ and $85 \%$ for SEM1 and SEM2 respectively. This result could be explained by the results of question one regarding their perceived knowledge where CSR had the lowest scores; if students do not understand CSR, they may not be able to judge whether or not they would like to learn about it.

While the interest is high for sustainability and ethics, the lower scores or suggested lack of interest in learning about CSR contradict the importance students place on CSR both in their academic studies and in their future professional lives. Students in both semesters 
ranked the importance of CSR extremely high, from $88 \%$ to $94 \%$ for its importance as students to $96 \%$ and $99 \%$ for future professionals, yet their interest in learning about these same topics during their time in HE is ambiguous at best.

Regarding how students perceived implementing ECSRS topics in their international hospitality management program, the results were mixed with the strongest responses coming from one course or embedded in all courses. For SEM1 students, the score was tied between the top options at 40 choices each. For SEM2, embedding ECSRS in all courses scored 48, while offering only one course scored 35 . These results are similar to those of previous studies and can be confirmed as common choices for implementing ECSRS in HE institutions. The choice of external ECSRS showed similar results between the semesters with 18 and 20 votes respectively. The greatest difference in implementation came from the electives. While only 19 SEM1 students chose this option, 32 SEM2 students chose an elective for learning ECSRS. One explanation could be the fact that SEM2 students have had one semester longer to understand the academic program which includes electives in the $6^{\text {th }}$ semester or final year of the program. While this is still four semesters away, they may have already started considering the type of electives they would like to take.

\section{Conclusions and Implications}

Based on this study, there seems to be a gap between existing knowledge, level of interest, and importance of ECSRS in first year students' perceptions. While the students are overwhelmingly convinced by the importance of ECSRS, especially CSR, they are not terribly interested in learning about it. However, when asked where ECSRS courses should be placed in the curriculum, the students again offered numerous suggestions for both the courses in which these topics could be covered and the semesters in which they would be most suited. This seemingly contradictory position on the interest and importance needs to be studied further. 
To respond to the research questions posited in the introduction:

RQ1: Are there differences between first and second semester students regarding their selfperceived knowledge of ECSRS? The response is yes, but not as substantially different as initially expected. In both semesters, there is a range of self-perceived knowledge with the highest knowledge scores recorded for ethics in both groups, followed by sustainability and CSR. However, second semester students ranked their self-perceived knowledge in both sustainability and CSR higher than first semester students. This could be explained by an exposure, albeit secondary, to concepts such as sustainability or CSR mentioned in courses in the second semester.

RQ2: Do first year students rate ECSRS as more important in their academic or professional lives? Based on the findings in this study, students in the first year of this international hospitality management program in Switzerland perceived the three topics of ECSRS as more important in their professional lives. While sustainability and ethics were perceived as more important for their academic lives, all three topics ranked between $95 \%$ and $99 \%$ for their professional lives. As seen in the literature, one of the main roles of HE is to prepare students firstly for their future careers and, secondly, to be 'change agents' in their respective fields. Since students rated the importance of ECSRS so highly for the professional careers, more emphasis should be placed on these topics within the HE curriculum and ECSRS initiatives should be encouraged both on and off campus through internships, guest speakers, and community service projects.

RQ3: Which of the three topics of ECSRS is deemed most important by first year students?

All scores and responses combined, sustainability ranked as the most important topic followed closely by ethics and, in a solid third place, CSR by first year students for both their academic and professional careers. There are several potential explanations for this result. First, students ranked sustainability highest in the self-perceived knowledge. Thus, if they know more about 
the topic, they may equally find it more important to their lives. Secondly, words like 'sustainability', 'sustainable development', or 'green' initiatives appear frequently in the media which is, as seen in this paper, the second highest place after school where students gain their information about ECSRS. Finally, when asked to name specific sustainable initiatives taken on campus, students cited most often recycling, PET machine, and solar panels indicating that they know of sustainable initiatives on campus. Their most cited future sustainable initiative was removing plastic cups from the campus.

RQ4: How would students prefer ECSRS to be introduced into the curriculum?

Based on this survey, students had mixed expectations as to how ECSRS could or should be introduced into the curriculum. Currently, there is no specific course or strategy for embedding ECSRS into the curriculum at this international hospitality management school in Switzerland. For this reason, student responses offer rich information for future implementation of ECSRS on campus. From the responses, one course or embedded in all courses were the most preferred methods for implementation of ECSRS, although one elective or an external option were also cited as viable solutions. This suggests a range of potential solutions deriving directly from one important stakeholder group, i.e. students, which could be implemented within the hospitality management program.

\section{Limitations and Future Studies}

From this study, it is clear that students see the relevance and believe in the importance of ECSRS in their academic lives and for their future careers. Based on their feedback, a working group consisting of students, professors, management, and external stakeholders such as alumni and industry experts could be formed to discuss the best ways to implement ECSRS into the curriculum. However, this study had several limitations. While the population was diverse in nationality and gender and representative of the larger student population, it was reserved to only first year students in their first or second semester of 
studies. A future project could involve all students in all semesters to gauge if their knowledge and interest is similar to the findings shown here. The survey was conducted in one language of one international hospitality management program in Switzerland. A further study could include other language groups, in the specific case of this school, French, as well to compare their knowledge and interest in ECSRS or broaden out to include other hospitality schools as well. While this study examined how ECSRS could be implemented according to student preferences, the specific content and topics of ECSRS were not addressed. This, too, could be the subject of a future study. 


\section{References}

Brundtland Report. (1987). Our Common Future. Retrieved from World Commission on Environment and Development (WCED).

Chaplin, G., \& Wyton, P. (2014). Student engagement with sustainability: Understanding the value-action gap. International Journal of Sustainability in Higher Education, 15(4), 404- 417. doi: 10.1108/IJSHE-04-2012-0029

Cho, C., Dyllick, T., Flakenstein, M., Killian, S., O’Regan, P., Reno, M., ... Watson, M. (2014). Ethics, responsibility, and sustainability (ERS) in business school accreditation: Peer-learning perspectives. Management Education for the World $50+20$. Retrieved from www.aomlists.pace.edu/.../wa.exe?

Costanza, D., \& Finkelstein, L. M. (2015). Generationally based differences in the workplace: Is there a there there? Industrial and Organizational Psychology, 8(3), 308-323. doi: 10.1017/iop.2015.15

Drayson, R. (2015). Student attitudes towards, and skills for, sustainable development. The Higher Education Academy. Retrieved from www.heacademy.ac.uk

European Commission (2001). Promoting a European Framework for Corporate Social Responsibility. Green paper. Luxembourg: Office for Official Publications of the European Commission.

Fernandez-Fernandez, J. L., \& Sanjuan, A. B. (2010). The presence of business ethics and CSR in higher education curricula for executives: The case of Spain. Journal of Business Ethics Education, 7, 25- 38.

Gonzalez-Rodriguez, M. R., Diaz-Fernandez, M. C., Pawlak, M., \& Simonetti, B. (2013).

Perceptions of university students of corporate social responsibility. Qualitative Quantitative, 47, 2361- 2377. doi: 10.1007/s11135-012-9781-5

Hesselbarth, C., \& Schaltegger, S. (2014). Educating change agents for sustainabilityLearnings from the first sustainability management master of business administration. Journal of Cleaner Production, 62, 24- 36. doi: 10.1016/j.jclepro.2013.03.042 
Kopnina, H., \& Meijers, F. (2014). Education for sustainable development (ESD): Exploring theoretical and practical challenges. International Journal of Sustainability in Higher Education, 15(2), 188- 207. doi: 10.1108/IJSHE-07-2012-0059

Lau, C. L. L. (2010). A step forward: Ethics education matters! Journal of Business Ethics, 92, 565- 584. doi: 10.1007/s10551-009-0173-2

Lozano, R., Ceulemans, K., Alonso-Almeida, M., Huisingh, D., Lozano, F. J., Waas, T., ... Huge, J. (2015). A review of commitment and implementation of sustainable development in higher education: Results from a worldwide study. Journal of Cleaner Production, 108, 1-18. doi: 10.1016/j.jclepro.2014.09.048

Lyons, S., Urick, M., Kuron, L., \& Schweiter, L. (2015). Generational differences in the workplace: There is complexity beyond the stereotypes. Industrial and Organizational Psychology, 8(3), 346-356. doi: 10.1017/iop.2015.48

Matten, D., \& Moon, J. (2004). Corporate social responsibility education in Europe. Journal of Business Ethics, 54, 323- 337.

Nicholls, J., Hair, J. F. Jr., Ragland, C. B., \& Schimmel, K. E. (2013). Ethics, corporate social responsibility, and sustainability education in AACSB undergraduate and graduate marketing curricula: A benchmark study. Journal of Marketing Education, 35(2), 129140. doi: $10.1177 / 0273475313589557$

Othman, R., \& Othman, R. (2014). Higher education institutions and social performance: Evidence from public and private universities. International Journal of Business and Society, 15(1), 1- 18.

PRME Principles for Responsible Management Education. (2016). Retrieved from http://www.unprme.org/about-prme/the-six-principles.php

Rundle-Thiele, S. R., \& Wymer, W. (2010). Stand-alone ethics, social responsibility, and sustainability course requirements: A snapshot from Australia and New Zealand. Journal of Marketing Education, 32(1), 5- 12. doi: 10.1177/0273475309345002

Savelyeva, T., \& Douglas, W. (2017). Global consciousness and pillars of sustainable development: A study on self-perceptions of the first-year university students. 
Seto-Pamies, D., \& Papaoikonomou, E. (2016). A multi-level perspective for the integration of ethics, corporate social responsibility and sustainability (ECSRS) in management education. Journal of Business Ethics, 136, 523-538. doi: 10.1007/s10551-014-2535-7

Sidiropoulos, E. (2014). Education for sustainability in business education programs: A question of value. Journal of Cleaner Production, 85, 472- 487. doi:

10.1016/j.jclepro.2013.10.040

Sleeper, B. J., Schneider, K. C., Weber, P. S., \& Weber, J. E. (2006). Scale and study of student attitudes toward business education's role in addressing social issues. Journal of Business Ethics, 68, 381- 391. doi: 10.1007/s10551-006-9000-1

Stir, J. (2006). Restructuring teacher education for sustainability: Student involvement through a 'strengths model'. Journal of Cleaner Production, 14, 830- 836. doi. 10.1016/j.jclepro.2005.11.051

Tormo-Carbo, G., Oltra, V., Segui-Mas, E., \& Klimkiewicz, K. (2016). How effective are business ethics/CSR courses in higher education? Conference Proceedings: $2^{\text {nd }}$ International Conference on Higher Education Advances, HEAd- 16, Valencia, Spain.

Verhulst, E., \& Lambrechts, W. (2015). Fostering the incorporation of sustainable development in higher education. Lessons learned from a change management perspective. Journal of Cleaner Production, 106, 189-204. doi:

10.1016/j.jclepro.2014.09.049

Yuan, X., \& Zuo, J. (2013). A critical assessment of higher education for sustainable development from students' perspectives: A Chinese study. Journal of Cleaner Production, 48, 108- 115. doi: 10.1016/j.jclepro.2012.10.041 
Appendix A: Tables

Table 1

Knowledge of ECSRS by SEM1 and SEM2 students

\begin{tabular}{l|l|l|l|l|l|l|l|l|l|l}
\hline $\begin{array}{l}\text { Knowledge of } \\
\text { ECSRS }\end{array}$ & 1 & 2 & 3 & 4 & 5 & 6 & 7 & 8 & 9 & 10 \\
\hline $\begin{array}{l}\text { Sustainability } \\
\text { SEM1 }\end{array}$ & 0 & 0 & 4 & 8 & 20 & 27 & 26 & 20 & 1 & 1 \\
SEM2 & 0 & 3 & 3 & 7 & 13 & 17 & 29 & 13 & 10 & 1 \\
\hline CSR & 13 & 16 & 19 & 22 & 11 & 15 & 9 & 2 & 0 & 1 \\
SEM1 & 3 & 9 & 10 & 17 & 19 & 18 & 13 & 4 & 2 & 1 \\
SEM2 & & & & & & & & & & \\
\hline Ethics & 1 & 3 & 1 & 6 & 18 & 15 & 26 & 28 & 6 & 3 \\
SEM1 & 0 & 2 & 0 & 2 & 6 & 10 & 29 & 28 & 15 & 4 \\
SEM2 & & & & & & & & & & \\
\hline
\end{tabular}

Table 2

Where ECSRS knowledge has been gained

\begin{tabular}{l|l|l|l|l|l|l|l}
\hline $\begin{array}{l}\text { Knowledge of } \\
\text { ECSRS }\end{array}$ & Parents & Friends & Media & School & Work & $\begin{array}{l}\text { Personal } \\
\text { research }\end{array}$ & $\begin{array}{l}\text { Never } \\
\text { learned }\end{array}$ \\
\hline $\begin{array}{l}\text { Sustainability } \\
\text { SEM1 }\end{array}$ & 42 & 14 & 66 & 78 & 2 & 9 & 0 \\
SEM2 & 35 & 13 & 68 & 76 & 3 & 5 & 0 \\
\hline CSR & & & & & & & \\
SEM1 & 14 & 7 & 28 & 69 & 4 & 0 & 13 \\
SEM2 & 11 & 4 & 47 & 64 & 5 & 2 & 7 \\
\hline Ethics & & & & & & & \\
SEM1 & 87 & 32 & 33 & 63 & 2 & 1 & 1 \\
SEM2 & 91 & 41 & 26 & 60 & 2 & 5 & 0 \\
\hline
\end{tabular}

Table 3

Interest in learning about ECSRS by SEM1 and SEM2

\begin{tabular}{l|l|l|l|l|l|l|l|l|l|l}
\hline $\begin{array}{l}\text { Interest in } \\
\text { ECSRS }\end{array}$ & 1 & 2 & 3 & 4 & 5 & 6 & 7 & 8 & 9 & 10 \\
\hline $\begin{array}{l}\text { Sustainability } \\
\text { SEM1 }\end{array}$ & 0 & 0 & 1 & 0 & 5 & 17 & 23 & 23 & 24 & 14 \\
SEM2 & 0 & 0 & 0 & 3 & 4 & 10 & 21 & 22 & 21 & 15 \\
\hline CSR & & & & & & & & & & \\
SEM1 & 0 & 1 & 2 & 6 & 22 & 10 & 23 & 24 & 13 & 6 \\
SEM2 & 2 & 1 & 1 & 2 & 8 & 17 & 21 & 16 & 17 & 11 \\
\hline Ethics & & & & & & & & & & \\
SEM1 & 0 & 0 & 2 & 2 & 14 & 4 & 24 & 29 & 19 & 13 \\
SEM2 & 0 & 2 & 1 & 2 & 3 & 7 & 15 & 29 & 19 & 18 \\
\hline
\end{tabular}


Table 4

Importance of ECSRS as students for SEM1 and SEM2

\begin{tabular}{l|l|l|l|l|l|l|l|l|l|l}
\hline $\begin{array}{l}\text { Importance of } \\
\text { ECSRS }\end{array}$ & 1 & 2 & 3 & 4 & 5 & 6 & 7 & 8 & 9 & 10 \\
\hline $\begin{array}{l}\text { Sustainability } \\
\text { SEM1 }\end{array}$ & 0 & 0 & 0 & 1 & 1 & 11 & 13 & 27 & 26 & 28 \\
SEM2 & 0 & 1 & 0 & 1 & 3 & 5 & 14 & 14 & 29 & 29 \\
\hline CSR & & & & & & & & & & \\
SEM1 & 0 & 0 & 2 & 1 & 12 & 10 & 14 & 35 & 17 & 18 \\
SEM2 & 0 & 2 & 1 & 0 & 4 & 8 & 12 & 23 & 19 & 28 \\
\hline Ethics & & & & & & & & & & \\
SEM1 & 0 & 0 & 0 & 1 & 2 & 10 & 12 & 26 & 25 & 30 \\
SEM2 & 1 & 0 & 3 & 0 & 5 & 2 & 7 & 17 & 28 & 32 \\
\hline
\end{tabular}

Table 5

Importance of ECSRS as future professionals

\begin{tabular}{l|l|l|l|l|l|l|l|l|l|l}
\hline $\begin{array}{l}\text { Importance of } \\
\text { ECSRS }\end{array}$ & 1 & 2 & 3 & 4 & 5 & 6 & 7 & 8 & 9 & 10 \\
\hline $\begin{array}{l}\text { Sustainability } \\
\text { SEM1 }\end{array}$ & 0 & 0 & 0 & 0 & 3 & 2 & 10 & 24 & 24 & 44 \\
SEM2 & 0 & 0 & 1 & 0 & 0 & 3 & 11 & 10 & 29 & 42 \\
\hline CSR & & & & & & & & & & \\
SEM1 & 0 & 0 & 0 & 0 & 4 & 4 & 12 & 23 & 28 & 34 \\
SEM2 & 0 & 0 & 0 & 0 & 1 & 3 & 5 & 13 & 27 & 47 \\
\hline Ethics & & & & & & & & & & \\
SEM1 & 0 & 0 & 0 & 1 & 0 & 1 & 13 & 22 & 26 & 44 \\
SEM2 & 0 & 0 & 1 & 1 & 3 & 2 & 8 & 8 & 31 & 42 \\
\hline
\end{tabular}

URL: http://mc.manuscriptcentral.com/jhte Email: agrayson@chrie.org 